\title{
TOXIC EPIDERMAL NECROLYSIS INDUCED BY CARBAMAZEPINE: A CASE STUDY
}

\author{
JAHIRUL ISLAM LASKAR*, PINAKI CHAKRAVARTY, BABUL DEWAN
}

Department of Pharmacology, Silchar Medical College and Hospital, Silchar, Assam, India. Email: dr.jahirul@gmail.com

Received: 10 March 2017, Revised and Accepted: 15 April 2017

\begin{abstract}
Objectives: The objective of this case study is to evaluate the importance of detection, assessment, and reporting of an adverse drug reaction and to improve the medication perseverance.
\end{abstract}

Methods: This is an observational type of case report which was observed and analyzed in Silchar Medical College and Hospital on regular ward rounds.

Results: A case report of toxic epidermal necrolysis due to carbamazepine (CBZ) administration by a 47-year-old male patient who presented as a follow-up case of ischemic stroke. Causality assessment of the event done with Naranjo' causality assessment scale suggests to be "Probable."

Conclusion: Daily, CBZ is being increasingly prescribed for control of pain in neuralgias and diabetic neuropathy, apart from control of seizures. Awareness about the drugs implicated in life-threatening drug reactions will help physicians in preventing them by cautious use of the drugs. Moreover, proper counseling to the patient regarding the use of medications is of utmost importance, in such life-threatening conditions where treatment guidelines remain indistinct.

Keywords: Toxic epidermal necrolysis, Carbamazepine, Adverse drug reaction, Probable.

(C) 2017 The Authors. Published by Innovare Academic Sciences Pvt Ltd. This is an open access article under the CC BY license (http://creativecommons. org/licenses/by/4. 0/) DOI: http://dx.doi.org/10.22159/ajpcr.2017.v10i7.18406

\section{INTRODUCTION}

Toxic epidermal necrolysis (TEN) and Stevens-Johnson Syndrome (SJS) affecting approximately 1 or 2/1,000,000 annually, and are considered medical emergencies as they are potentially fatal conditions. Drugs are assumed or identified as the main cause of SJS/TEN in most cases, but Mycoplasma pneumoniae and herpes simplex virus infections are also well-documented causes alongside (mostly rare cases) in which the etiology remains unknown [1]. This disease affects the skin and mucous membranes at the skin, mouth, eyes, and genitals. It is severe and highly weakening adverse drug reactions (ADR) [2]. SJS disorder is more likely to occur in people with highly active anti-retroviral therapy regimens [3].

TEN and SJS are two forms of the same life-threatening skin disease induced by an immune complex mediated hypersensitivity reaction. In SJS, a patient has blistering of mucous membranes, typically in the mouth, eyes, and genitalia and widespread small blisters that arise as erythematous or purpuric maculae. There is a similar blistering of mucous membranes, but in addition, the entire top layer of the skin (the epidermis) peels off in sheets forming larger areas in the body of TEN patients [4]

TEN and SJS are rare but critically ill, severe cutaneous ADR. The mortality rates are about $10 \%$ in SJS, $10-30 \%$ in overlapping SJS/TEN, and $30 \%$ in TEN [5].

TEN and SJS are classified into type IVc hypersensitivity reactions according to a modified Gell and Coombs classification by Adam et al. [6] The main effector cells are CD8+ cytotoxic T lymphocytes, CD4+ T cells, natural killer cells, and natural killer T cells. Massive release of granulysin, perforin, and granzyme $\mathrm{B}$ is involved in the pathogenesis [7].

Patients develop an acute exanthemous lesions, which progresses toward a widespread blistering (TEN) or more limited purpura, vesicles (SJS) and erosion of the skin and mucous membranes, resulting from apoptosis of keratinocytes. The incidence of SJS is estimated to be 1-6 cases per million person-years and of TEN at 0.4-1.2 cases per million person-years. Various drugs are reported to be associated with a high risk for SJS and TEN. These include several antiepileptic agents, especially carbamazepine (CBZ), phenytoin, phenobarbital and lamotrigine, antibacterials, anti-inflammatory drugs of the oxicam family and allopurinol $[8,9]$

The Pharmacovigilance Working Team recommended key elements of warnings for the product information of CBZ, lamotrigine, phenobarbital, phenytoin, meloxicam, piroxicam, tenoxicam, regarding their rare risk of life- threatening SJS for the early detection of these adverse reactions and subsequent permanent discontinuation of the medicine to improve their outcomes [10]. Certain human leukocyte antigen (HLA) types are sometimes associated with increased risk of SJS, including HLA B1502 [11].

However, recent publications and postmarketing data suggest that CBZ associated SIS/TEN occurs at a much higher rate in some Asian populations, about 2.5 cases per 1,000 new exposures. The early symptoms of fever, malaise, cough, stinging eyes and a sore throat are often confused with an upper respiratory tract infection. This rapidly progresses to erythematous macules and targeted lesions, epidermal detachment, and mucositis. Early painful erythema and blisters of the palms and soles are a hallmark of SJS. Drugs such as anti-epileptics mainly phenytoin and CBZ were responsible for the majority (44\%) of the ADR [12].

CBZ is one among the routinely administered medication for the treatment of simple and complex partial seizures, neuralgia and alcohol withdrawal syndrome. The drug has anticonvulsive and anticholinergic properties by reducing excessive nerve signals within the brain and restoring the conventional balance of nerve activity. Side effects include conditions such as ataxia, vertigo, drowsiness, confusion, headache, maculopapular rash, erythema multiforme, SJS, TEN, xerostomia 
(gastrointestinal), and aplastic anemia [13,14]. We are reporting such an interesting case of CBZ induced TEN at a tertiary care hospital in the southern part of Assam. The details of this case are discussed and analyzed henceforth.

\section{CASE DESCRIPTION}

The patient is a 47-year-old male, a follow-up case of Ischemic stroke who was diagnosed as Rt/middle cerebral artery (MCA) Territory infarction with (Lt) sided Hemiparesis on Jan 2015. He was treated conservatively and was on Tab. Ecosprin AV-75 (clopidogrel - $300 \mathrm{mg}$ and aspirin $-75 \mathrm{mg}$ ) one tab once daily after dinner and was advised to continue the same till next follow-up. After about 5 months he visited a neurologist with the residual weakness of the left side of the body. He was prescribed Tab. CBZ (Zeptol CR) $200 \mathrm{mg}$ and was advised to take a half tablet once daily after dinner for 10 days and then one tablet once daily after dinner for next 10 days. After taking the drug CBZ for 11 days (i.e., half tab once daily for 10 days and one tab once daily for just another 1 day) a total of 11 doses, he developed widespread, pruritic, erythematous, papular lesions, and blackish scaly skin all over the body. It was associated with fever and headache. An excess peeling of skin along with intense inflammation of eyes, lips, nose, genitalia, and oral cavity also occurred. On physical examination, the patient presented with a temperature of $39^{\circ} \mathrm{C}$ and a blood pressure of $100 / 70 \mathrm{mmHg}$. On examination, there were ulcerated lesions on the oral mucosa. Extensive erythematous plaques were present over the rest of the body (more than $30 \%$ of the body surface). The patient was subsequently admitted in the Department of Dermatology at Silchar Medical College and Hospital with a diagnosis of TEN probably due to CBZ. He had no personal or family history of skin diseases, neither was he an allergic to any known allergens, food or drugs.

Causality assessment of the event was done with Naranjo' causality assessment scale (total score - 7) suggests a causal relationship between the drug and reaction is "Probable."

Physical examination revealed hypotension (B.P-100/64 $\mathrm{mm}$ of $\mathrm{Hg}$ ), tachycardia (pulse rate 110 beats/minutes), and tachypnea (respiratory rate 52/minutes). The patient was febrile. Clinical examination of the skin revealed a generalized peeling of the skin with crusting almost all over the body including scalp and genitalia (Figs. 1-3). The Nikolsky sign was positive. The erythematous rash was present almost all over the body with an epidermal detachment of $70 \%$ of the body surface area. Loss of eyelashes, congestion of conjunctiva with mucopurulent discharge and exposure keratitis were also present. Liver and spleen were not palpable. There was no associated lymphadenopathy. Liver function tests showed elevated aspartate aminotransferase 175 (normal 10-45) U/L and elevated alanine aminotransferase 94 (normal 6-48) U/L. His total white blood cell count was $4.25 \times 10^{9} / \mathrm{L}$ (normal $4-10 \times 10^{9} / \mathrm{L}$ ). No atypical lymphocytosis or eosinophilia was noted. Platelet count was normal. Hemoglobin was low $(10.2 \mathrm{~g} / \mathrm{dl})$. Serum creatinine was $1.4 \mathrm{~g} / \mathrm{dL}$. The patient had hyponatremia $\left(\mathrm{Na}^{+} 115 \mathrm{mmol} / \mathrm{L}\right)$ and hyperkalemia $\left(\mathrm{K}^{+} 7.2 \mathrm{mmol} / \mathrm{L}\right)$, which was corrected appropriately.

The clinical impression was TEN induced by CBZ. The suspected medication was stopped immediately. He was given high dose intravenous (iv) dexamethasone (dexona) and pheniramine maleate (avil) intramuscular injection twice daily, iv ondansetron (emigo) SOS, IVF-DNS-RL iv slowly to maintain the fluid and electrolytic balance the fluid topical application of clonate (clobetasone) lotion twice daily, clinical lotion thrice daily, kenacort (triamcinolone) oral paste twice daily, betadine mouthwash once a day was also included in the treatment schedule. The patient was made to lie down on the sterile banana leaf to prevent sticking of the skin to the bed. Eye lesions were treated with topical antibiotic preparations (ciprofloxacin, gentamicin, chloramphenicol, and moxifloxacin + dexamethasone) and ocular lubricant solution (lacrigel). Eyes were covered with saline-soaked sterile pads. The patient was also treated with parenteral antibiotics

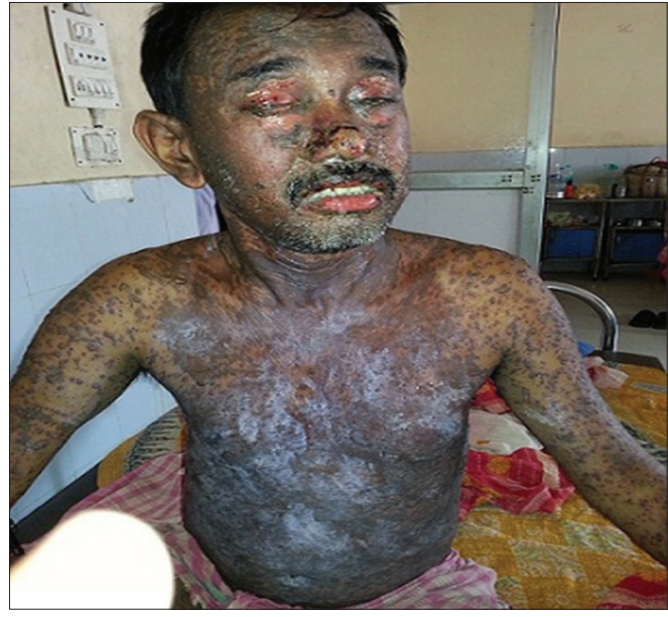

Fig. 1: Edema and crusting of the lips, nose, and inflammation of eyes

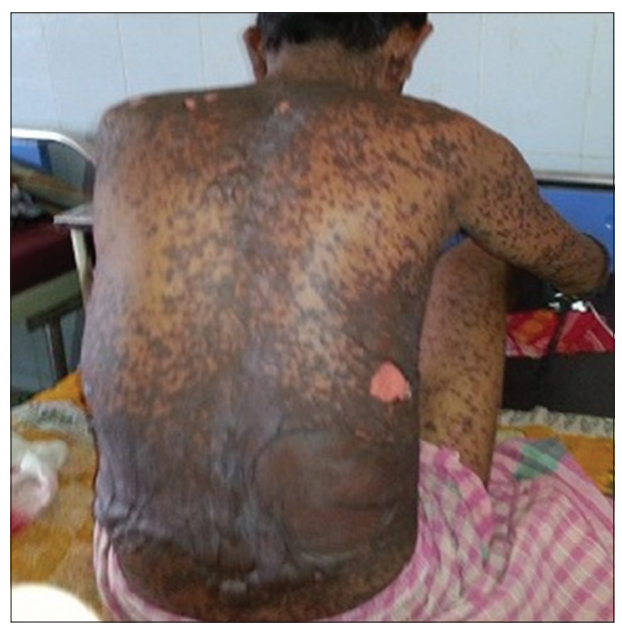

Fig. 2: Peeling of skin and erythematous lesions of skin involving the back

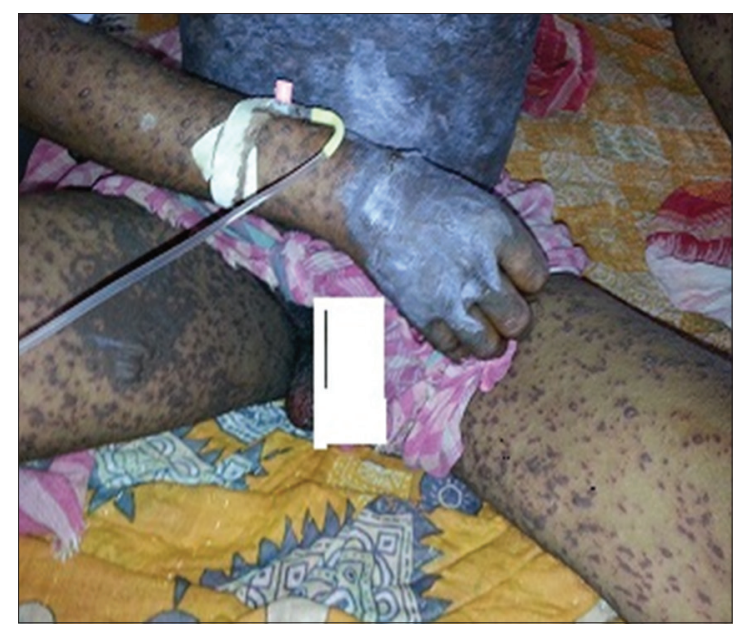

Fig. 3: Erythematous purpuric macular lesions involving the upper limbs, thighs, and genital area

piperacillin+tazobactum combination and linezolid. Supportive treatment included parenteral opioids (fentanyl, pentazocine) for pain management, iv fluids, and iv albumin. Nutrition was maintained by giving protein powder preparation through Ryle's tube. He was switched 
over to oral betamethasone once the lesions started healing. Tablet Betamethasone was slowly tapered and stopped after 4 weeks. Lesions healed with post-inflammatory hyperpigmentation approximately by the $16^{\text {th }}$ day. After 1 month, the progression of the skin lesions halted, and general condition of the patient improved significantly.

The following figures depict the actual condition of the patient with CBZ induced TEN.

\section{DISCUSSION}

TEN also known as Lyell's syndrome was first described by Lyell in 1956. The word toxic alludes to the constitutional symptoms while necrolysis refers to the necrosis and detachment of the full thickness of the epidermis [15]. TEN and SJS are related mucocutaneous disorders with an estimated incidence of 0.4-1.2 patients per year. Both the diseases are associated with higher rates of morbidity and mortality. Overall mortality for SJS ranges from $5 \%$ to $25 \%$, and that for TEN ranges from $15 \%$ to $40 \%$. In TEN, maximal skin involvement with a rash is reached within 4 days, and sometimes within hours, whereas the corresponding time for SIS is 1-14 days. About $90 \%$ of patients with TEN develop painful erosions in their mucosal membranes, approximately $85 \%$ have conjunctival lesions, and about $35 \%$ of those who survive experience ocular sequelae [9].

In this case, the patient was admitted to the hospital with severe rashes, peeling of skin as scales all over the body. On physical examination, the patient was dehydrated and poorly nourished. This excess peeled skin was mainly observed on neck, chest, abdomen, lower back, thighs, genitalia, and over the head. The patient dehydrated state was attributed to the detachment of epidermal cells and their secretions. Drugs are the most common cause accounting for about $65-80 \%$ of the cases. An immune mechanism is implicated in the pathogenesis, but its nature is still unclear. It is primarily directed at drug modified epidermal cells [16]. In this report, the patient was a follow-up case of Ischemic stroke R/MCA Territory with (L) Hemiparesis diagnosed on January 2015. He came for treatment for his LT sided residual weakness on May 2015. On the $11^{\text {th }}$ day of his follow-up treatment, the patient had his $11^{\text {th }}$ dose on the evening after dinner at around 9 PM. Within a span of 4-5 hrs, he developed severe rashes and blisters all over the body, the patient visited his doctor next morning, who advised him to stop the suspected medication and attend the Dermatology OPD at Silchar Medical College and Hospital. Accordingly, the patient rushed to the dermatology OPD of Silchar Medical College and Hospital, where the physician, on taking a detailed history and through physical examination, suspected it to be a case of TEN, probably due to CBZ administration. The patient was admitted immediately and initiated supportive therapy without further delay.

The following diagnostic criteria must be fulfilled for a case to be labeled as TEN.

1. Bullae or erosions involving more than $20 \%$ of body surface area or three different anatomical sites.

2. Skin peeling in sheets of more than $3 \mathrm{~cm}$.

3. Involvement of non-exposed skin.

4. Mucous membranes involvement.

5. Skin tenderness within $48 \mathrm{hrs}$ of rash.

6. Biopsy confirmation within 48 hrs.

7. Fever.

8. Bullae arising on an erythematous background.

9. Exclusion of Staphylococcal scalded skin syndrome.

Investigations usually show leukocytosis, albuminuria, water, and electrolyte imbalance and raised transaminases [17].

Although the pathogenesis of these lesions is unknown, a number of hypothesis has been put forward [18]. Treatment consisted of supportive measures such as removal of precipitating agents, good nursing care, laying down the patient on a ripple bed, care of the eyes and mouth to prevent scarring and infections, along with maintenance of fluid, and electrolyte balance. iv fluids were given for 3 days consecutively. iv fluids were supplemented with ORS. The patient was prescribed antibiotics iv for 3 days and switched over to oral formulations to prevent further infections. The patient was put on a high-protein diet. After several days of treatment, the patient showed signs of improvement and his overall general health conditions also improved.

\section{CONCLUSION}

TEN is considered as a life-threatening complication and a medical emergency. Its association with the use of CBZ may have a familial tendency. Moreover, proper counseling regarding the use of medications is of utmost importance, in such life-threatening conditions where treatment guidelines remain unclear. It is also advisable to give information about adverse drug reaction to the patients who suffered from such serious reactions in the past and reporting the same to the concerned authority.

Daily, CBZ is being increasingly prescribed for control of pain in neuralgias and diabetic neuropathy apart from using it as an antiseizures agent. Awareness about the drugs implicated in life-threatening drug reactions will help physicians as well other health-care providers in early detection and prevention of ADRs by cautious use of such drugs.

\section{ACKNOWLEDGMENTS}

The author extends thanks ADRs Monitoring Centre, Pharmacovigilance Programme of India under Indian Pharmacopoeia Commission and colleagues from the Department of Dermatology Silchar Medical College and Hospital for their help and support during the study.

\section{REFERENCES}

1. Harr T, French LE. Toxic epidermal necrolysis and Stevens-Johnson syndrome. Orphanet J Rare Dis 2010;5:39.

2. Kurmanji JM, Younus MM, Al-Amiry MH. Steven Johnson syndrome: Three cases reported in Iraq. Int J Pharm Pharm Sci 2012;4(4):1-2.

3. Bhanukumar M, Menon VB, Kurian J. Nevirapine induced Stevens Johnson syndrome: A case report. Int J Pharm Pharm Sci 2015;7(9):520-1.

4. Hussain W, Craven NM. Toxic epidermal necrolysis and StevensJohnson syndrome. Clin Med (Lond) 2005;5(6):555-8.

5. Kim SH, Lee KW, Song WJ, Kim SH, Jee YK, Lee SM, et al. Carbamazepine-induced severe cutaneous adverse reactions and HLA genotypes in Koreans. Epilepsy Res 2011;97(1-2):190-7.

6. Adam J, Pichler WJ, Yerly D. Delayed drug hypersensitivity: Models of T-cell stimulation. Br J Clin Pharmacol 2011;71(5):701-7.

7. Wei CY, Ko TM, Shen CY, Chen YT. A recent update of pharmacogenomics in drug-induced severe skin reactions. Drug Metab Pharmacokinet 2012;27(1):132-41.

8. Bastuji-Garin S, Rzany B, Stern RS, Shear NH, Naldi L, Roujeau JC. Clinical classification of cases of toxic epidermal necrolysis, StevensJohnson syndrome, and erythema multiforme. Arch Dermatol 1993;129(1):92-6.

9. Roujeau JC, Kelly JP, Naldi L, Rzany B, Stern RS, Anderson T, et al. Medication use and the risk of Stevens-Johnson syndrome or toxic epidermal necrolysis. N Engl J Med 1995;333(24):1600-7.

10. The CHMP Pharmacovigilance Working Party (PhVWP) Plenary Meeting. 19-21, September; 2011. Available from: http://www.ema. europa.eu/ema/index.jsp?curl= pages/news_and_events/news/2011/09/ news detail 001338.jsp\&murl=menus/news and events/news and events.jsp\&mid $=$ WC0b01ac058004d5c1

11. Kandil AO, Dvorak T, Mignano J, Wu JK, Zhu JJ. Multifocal StevensJohnson syndrome after concurrent phenytoin and cranial and thoracic radiation treatment, a case report. Radiat Oncol 2010;5:49.

12. Santhosh YL, Naveen MR, Satish Kumar BP. A case report on carbamazepine induced Steven Johnson syndrome. World J Pharm Sci 2013;1(1):19-20.

13. Eland IA, Dofferhoff AS, Vink R, Zondervan PE, Stricker BH. Colitis may be part of the antiepileptic drug hypersensitivity syndrome. Epilepsia 1999;40(12):1780-3.

14. Bosman T, Vonck K, Claeys P, Van Vlierberghe H, De Clercq M, De Reuck J, et al. Enter colitis: An adverse event in refractory epilepsy patients treated with levetiracetam? Seizure 2004;13(2):76-81. 
15. Hurwitz RM, Rivera HP, Gooch MH, Slama TG, Handt A, Weiss J. Toxic shock syndrome or toxic epidermal necrolysis? Case reports showing clinical similarity and histological seperation. J Am Acad Dermatol 1982;7(2):246-54

16. Roujeazu JC, Chosidow O, Saiag P, Guillaume JC. Toxic epidermal necrolysis (Lyell syndrome). J Am Acad Dermatol 1990;23(6):1039-58.

17. Qadir SN, Raza N, Qadir F. Drug induced toxic epidermal necrolysis: Two case reports. Cases J 2009;2(7765):7765.

18. Vittorio CC, Muglia JJ. Anticonvulsant hypersensitivity syndrome. Arch Intern Med 1995;155(21):2285-90. 